\title{
Correction to: Consequences of Childhood Bullying on Mental Health and Relationships for Young Adults
}

Ellen W. deLara ${ }^{1}$

Published online: 2 August 2019

(c) Springer Science+Business Media, LLC, part of Springer Nature 2019

\section{Correction to: Journal of Child and Family Studies} https://doi.org/10.1007/s10826-018-1197-y

The original version of this article unfortunately contained a mistake. On page 9, the text "Of importance, the definitions of bullying offered by participants were parallel to the standard research definitions currently utilized in the field" should read as "Of importance, the definitions of bullying offered by participants were NOT (emphasis added) parallel to the standard research definitions currently utilized in the field".

The original article can be found online at https://doi.org/10.1007/ s10826-018-1197-y.

Ellen W. deLara

edelara@syr.edu

1 School of Social Work, White Hall, Syracuse University,

Syracuse, NY 13244, USA 